\title{
Optimisation of sample treatment for arsenic speciation in alga samples by focussed sonication and ultrafiltration
}

\author{
S. García Salgado, M.A. Quijano Nieto, M.M. Bonilla Simón \\ Departamento de Ingenieria Civil, Tecnologia Hidráulica y Energética, Escuela Universitaria de Ingenieros Técnicos de Obras Páblicas. \\ Universidad Politécnica de Madrid, Alfonso XII 3 y $5,280 / 4$ Madrid. Spain
}

\begin{abstract}
A procedure for arsenic species fractionation in alga samples (Sargassum fulvellum, Chlorella vulgaris, Hizikia fusiformis and Laminaria digitata) by extraction is described. Several parameters were tested in order to evaluate the extraction efficiency of the process: extraction medium, nature and concentration (tris(hydroxymethyl)aminomethane, phosphoric acid, deionised water and water/methanol mixtures), extraction time and physical treatment (magnetic stirring, ultrasonic bath and ultrasonic focussed probe). The extraction yield of arsenic under the different conditions was evaluated by determining the total arsenic content in the extracts by ICP-AES. Arsenic compounds were extracted in $5 \mathrm{~mL}$ of water by foeussed sonication for $30 \mathrm{~s}$ and subsequent centrifugation at $14,000 \times g$ for $10 \mathrm{~min}$. The process was repeated three times. Extraction studics show that soluble arsenic compounds account for about $65 \%$ of total arsenic.

An ultrafiltration process was used as a clean-up method for chromatographic analysis, and also allowed us to determine the extracted arsenic fraction with a molecular weight lower than $10 \mathrm{kDa}$, which accounts for about $100 \%$ for all samples analysed.

Speciation studies were carried out by HPLC-ICP-AES. Arsenic species were separated on a Hamilton PRP-X100 column with $17 \mathrm{mM}$ phosphate buffer at $\mathrm{pH} 5.5$ and $1.0 \mathrm{~mL}$ min ' flow rate. The chromatographic method allowed us to separate the specics As(III), As(V), MMA and DMA in less than $13 \mathrm{~min}$, with detection limits of about $20 \mathrm{ng}$ of arsenic per species, for a sample injection volume of $100 \mu \mathrm{L}$. The chromatographic analysis allowed us to identify $\Lambda \mathrm{s}(\mathrm{V})$ in Hizikia $\left(46 \pm 2 \mu \mathrm{g} \mathrm{g}^{-1}\right)$, Sargassum $\left(38 \pm 2 \mu \mathrm{g} \mathrm{g}^{-1}\right)$ and Chlorella $\left(9 \pm 1 \mu \mathrm{gg}^{-1}\right)$ samples. The species DMA was also found in Chlorella alga $\left(13 \pm 1 \mu \mathrm{gg}^{-1}\right)$. I lowever, in Laminaria alga only an unknown arsenic species was detected, which eluted in the dead volume.
\end{abstract}

Keywords: Arsenic speciation; Extraction by focussed sonication; Ultrafiltration; Algae; HPLC-ICP-AFS

\section{Introduction}

Marine organisms can accumulate high arsenic concentrations, which may be harmful to humans. Hence, arsenic species need to be measured in seafood to establish the potential threat to consumers [1-3]. It is very well known that arsenic toxicity depends not only on the total concentration but also on the chemical species in which this element is present. Inorganic arsenic species (arsenite (As(IIl)) and arsenate (As(V))) are more toxic than the methylated arsenicals (monomethylarsonic acid (MMA) and dimethylarsinic acid (DMA)), followed by more complex organic arsenicals (arsenobetaine (AsB), arseno- choline ( $\mathrm{AsC}$ ), tetramethylarsonium ion $\left(\mathrm{TMAs}^{+}\right.$), arsenoribosides), which are considered to be non-toxic to living organisms $[4,5]$.

The main arsenic compounds found in seaweeds are arsenoribosides [5-7], which are considered to be non-toxic. However, some algae such as Sargassum sp. are known to contain high percentages of the potentially toxic inorganic arsenic [1]. Apart from health risk assessment, arsenic speciation knowledge in algae is important in order to elucidate the arsenic cycle within the marine environment [8]. Seaweeds play an important role in the arsenic cycle in marine ecosystems. As primary producers, algae are an important link between arsenic in water and other organisms in the food chain. It has been proposed that the arsenoribosides metabolism is an arsenobetaine source for higher organisms [9]. Since some of the proposed pathways for transformation of these compounds into arsenobetaine are 
yet to be substantiated [10]. further investigation on the fate of arsenoribosides within marine organisms is needed to fill this knowledge gap.

Algae are very popular in the Chinese and Japanese cuisine [11]. and nowadays their use is widespread in Occidental countries, due to their high mineral content and their recognized therapeutic properties. The high arsenic levels (about several milligrams per kilogram) present in some kinds of algae make necessary the determination of total arsenic concentration, as well as the evaluation of the arsenic species present in commercial brands of algae.

Detailed information concerning analytical methods for arsenic speciation can be found in several reviews $[3,12,13]$. Most of studies were focussed on the development of hyphenated techniques [14-17]. The main difficulty for arsenic speciation in solid samples is to achieve a quantitative extraction and the absence of species transformation. No systematic study of arsenic species extraction from algae has been so far reported in the literature. Many studies about arsenic in algae have used mixtures of water/methanol to extract arsenic species $[3,7,12,17-22]$. Even performing several extraction steps ( 3 or 4), arsenic recoveries are often low and variable (6-98\%). Sonication is commonly used in order to improve the characteristics of solid-liquid extraction methods $[3,4.16-23]$. However. few studies have used accelerated solvent extraction $[3,26]$ or microwave-assisted extraction $[17,24]$, which have shown to give better recoveries than sonication in ultrasonic bath. Ultrasonic probe provides 100 times higher energy than the ultrasonic bath [25], and thus its use generally allows us to reduce the extraction time. Few studies have applied an ultrasonic focussed probe for species extraction, but there are not any comparative studies that state clearly the achieved advantages.

This paper has three objectives to: (1) develop an ultrasonic focussed probe assisted extraction procedure for the isolation of arsenic species from alga samples; (2) characterise and quantify the soluble arsenic fraction by ultrafiltration with $10 \mathrm{kDa}$ cut-off filters: and (3) identify and quantify the toxic arsenic species present in alga samples by high performance liquid chromatography coupled to ICP-AES

\section{Experimental}

\subsection{Instrumentation}

Alga samples were digested for total arsenic determination using a MARS five microwave oven (CEM Corporation. Matthews, NC. USA).

The ICP-AES instnument used was a Liberty Series II Axial Sequential ICP-AES (Varian Australia Pty Ltd., Mulgrave, Vic., Australia). Before coupling the chromatographic system, the ICP-AES working conditions were optimised using a standard solution containing $1.0 \mathrm{mg} \mathrm{L}^{-1}$ of manganese. The arsenic signal was then optimised using a $1.0 \mathrm{mg} \mathrm{L}^{-1}$ arsenic standard solution.

The chromatographic system consisted of a Jasco PU-980 HPLC pump (Jasco. Tokyo. Japan) with a Rheodyne 7725 sixport sample injection valve fitted with a $100 \mu \mathrm{L}$ sample loop
(Rheodyne. CA, USA). Separations were carried out in a Hamilton PRP-X100 $(250 \mathrm{~mm} \times 4.1 \mathrm{~mm}, 10 \mu \mathrm{m}$. Phenomenex, Torrance, CA. USA) anionic exchange column.

The clromatographic system was then coupled to the ICPAES instnument by a polytetrafluoroetlylene capillary tube $(20 \mathrm{~cm}, 0.5 \mathrm{~mm}$, i.d.), which connected the column outlet to the Meinhard nebuliser inlet

Chromatographic signals were registered using a Star 800 Module Interface Box and processed using a Star software (Varian). Signal quantification was carried out in the peak area mode.

For molecular weight fractionation and algae extracts cleaning. $10 \mathrm{kDa}$ cut-off filters (Millipore, Bedford. MA. USA) and an Eppendorf centrifige $5804 \mathrm{R}$ (Hamburg. Germany) were used.

The $0.45 \mu \mathrm{m}$ Millipore nylon filters were used to filter all the HPLC solutions.

A sonopuls ultrasonic homogenizer (Bandelin. Fungilab S.A., USA) fitted with a HF-generator HD 2200 was used to extract the samples. The homogenizer was equipped with a titanium microtip of $3 \mathrm{~mm}$ diameter and the power was set to $20 \mathrm{~W}$. The frequency was fixed at $20 \mathrm{kHz}$.

A rotavapour $R-200$, with a waterbath $B-490$ and a vacuum system V-500 (Büchi Labortechnik AG, Flawil, Switzerland) was used to evaporate the solvent.

\subsection{Reagents and standard solutions}

Stock solutions of $1000 \mathrm{mgL}^{-1}$ arsenic were prepared by dissolving the respective amount of the pure compound in deionised water (Milli-Q system, Millipore, USA). As(III) and $\mathrm{As}(\mathrm{V})$ standards solutions were prepared from $\mathrm{NaAsO}_{2}$ and $\mathrm{Na}_{2} \mathrm{HAsO}_{4}$, respectively (Panreac, Barcelona, Spain), MMA from $\mathrm{CH}_{3} \mathrm{AsO}_{3} \mathrm{Na}_{2}$ (Supelco Park, Bellefonte, PA. USA) and DMA from $\left(\mathrm{CH}_{3}\right)_{2} \mathrm{AsNaO}_{2} \cdot 3 \mathrm{H}_{2} \mathrm{O}$ (Fluka, Neu Ulm. Germany). The stock solutions were kept at $4{ }^{\circ} \mathrm{C}$ in the dark. Working solutions were prepared daily and then diluted with deionised water to the final concentration.

The eluent used for the separations was phospluate buffer (pH 5.5) at a concentration of $17 \mathrm{mmol} \mathrm{L}^{-1}$. It was prepared by mixing independent solutions of $\mathrm{Na}_{2} \mathrm{HPO}_{4}$ and $\mathrm{NaH}_{2} \mathrm{PO}_{4}$ (Sigma Chemicals, St. Louis, MO, USA) until the desired $\mathrm{pH}$ was reached

All HPLC solutions were filtered and degassed before use.

$\mathrm{HNO}_{3}(70 \%)$, from Scharlau (Barcelona, Spain), was used to digest the samples

The extractant mixtures were prepared from deionised water and HPLC-grade methanol (Scharlau). Other reagents were obtained from Merck (Darmstadt, Germany).

\subsection{Alga samples}

The reference material NIES no. 9, certified for total arsenic $\left(115 \pm 9 \mu \mathrm{g} \mathrm{g}^{-1}\right)$, was a lyophilised Sargasso material, purchased from National Institute for Environmental Studies (Tsukuba Ibaraki. Japan). The alga samples analysed were the lyophilised Bioma-6 material (Chlorella vulgaris) provided by Umweltanalytik-Internationales Hochschulinstitut Zittau (Germany), and Hijiki (Hizikia fusiformis) and Laminaria (Lam- 
Table 1

ICP-AES and chromatographic operating conditions

\begin{tabular}{ll}
\hline ICP-AES & \\
Forward power & $1200 \mathrm{~W}$ \\
Photomultiplier tube voltage & $650 \mathrm{~V}$ \\
Coolant argon flow rate & $15.0 \mathrm{Lmin}^{-1}$ \\
Auxiliary argon flow rate & $1.50 \mathrm{Lmin}^{-1}$ \\
Nebulisation argon pressure & $180 \mathrm{kPa}$ \\
Nebuliser type & Meinhard concentric glass \\
Chromatograplic system & \\
Analytical column & Hamilton PRP-X100 \\
Mobile phase & Phosphate buffer $17 \mathrm{mM}$ at pH 5.5 \\
Flow rate & $1.0 \mathrm{~mL}$ min \\
Injection volume & $100 \mu \mathrm{L}$ \\
\hline
\end{tabular}

inaria digitata), acquired in Spanish markets. Commercial products were kept in their packages until their use. Hijiki and Laminaria were provided as dry material and capsules, respectively. Hijiki was triturated in a mill to a particle size of $125 \mu \mathrm{m}$ and Laminaria capsules were opened and placed in a polyethylene bottle before the analytical treatment

\subsection{Mineralization for total arsenic determination}

Total arsenic concentrations were determined. after digestion of the samples. by direct nebulisation into ICP-AES. Digestion was carried out placing approximately $250 \mathrm{mg}$ of the sample in a polytetrafluoroethylene reactor together with $10 \mathrm{~mL}$ of nitric acid $(70 \%, \mathrm{v} / \mathrm{v})$ and then treated in a microwave oven for $30 \mathrm{~min}$, applying $225 \mathrm{psi}$ of pressure and $210 \% \mathrm{C}$ of temperature. The digests were diluted with deionised water up to $25 \mathrm{~mL}$. The total arsenic concentration was determined under the conditions summarised in Table 1 by external calibration (in the range $0.25-2.5 \mathrm{mg} \mathrm{L}^{-1}$ of arsenic) at $188.979,193.696$ and $228.812 \mathrm{~nm}$ lines.

\subsection{Arsenic species determination}

\subsubsection{Leaching}

Approximately $200 \mathrm{mg}$ of alga sample were accurately weighed into a $25 \mathrm{~mL}$ centrifuge tube and $5 \mathrm{~mL}$ of deionised water were added. The tube was sonicated with the homogenizer for $30 \mathrm{~s}$, then centrifuged for $10 \mathrm{~min}$ at $14,000 \times g$ and the supernatant was replaced into a $50 \mathrm{~mL}$ round bottom flask. The extraction process was repeated two or three times, depending on total arsenic content of alga sample. Supernatants were mixed and evaporated in a rotavapour at a bath temperature of $60^{\circ} \mathrm{C}$. The residue obtained was dissolved in $4 \mathrm{~mL}$ of deionised water.

\subsubsection{Ultrafiltration}

Every final extract was processed through a $10 \mathrm{kDa}$ cut-off filter by centrifugation at $14.000 \times g$ and $20^{\circ} \mathrm{C}$ until the solution had passed through it. Finally. the filtrate was diluted to $10 \mathrm{~mL}$ with deionised water.

\subsubsection{Chromatographic separation}

Separation of arsenic species studied (As(III). As(V), MMA and DMA) was carried out on a Hamilton PRP-XI00 column. with $17 \mathrm{mM}$ phosphate buffer at $\mathrm{pH} 5.5$ and $1.0 \mathrm{~mL} \mathrm{~min}^{-1}$ flow rate as mobile phase.

The dead volume of the system was determined by passing $1.0 \mathrm{mgL}^{-1}$ lithium solution through the column. The $\mathrm{Li}^{+}$ion, which should not be retained on the column, was monitored by ICP-AES at $670.784 \mathrm{~nm}$ line. The dead volume of the system was calculated to be $2.19 \pm 0.01 \mathrm{~mL}$.

\subsubsection{Detection}

Arsenic species were detected by HPLC-ICP-AES, using the operating conditions given in Table 1 . The analytical peaks obtained were evaluated in terms of peak area by the standard addition method at $193.696 \mathrm{~nm}$ line.

\section{Results and discussion}

\subsection{Total arsenic determination}

The total arsenic content in alga samples was determined in order to evaluate the efficiency of the different procedures tested for arsenic species extraction. The results obtained are shown in Table 2. To check the accuracy. NIES no. 9 Sargasso reference material was also analysed. The results obtained $\left(106 \pm 6 \mu \mathrm{gg}^{-1}\right)$ shows that, at the $95 \%$ confidence level, there were no significant differences between the concentration found and the certified value. Therefore, the digestion method used has proven to be suitable for total arsenic determination in alga samples analysed.

\subsection{Arsenic speciation}

\subsubsection{Optimisation of arsenic compounds extraction}

Several experiments were carried out to extract the soluble arsenic compounds, and several parameters affecting the extraction from Sargasso material. such as solvent composition, extraction time, extractant volume and the specific method applied were tested.

The effect of extraction time was studied by varying this parameter for deionised water extraction $(5 \mathrm{~mL})$ applying magnetic stirring for $15 \mathrm{~min}$ up to $12 \mathrm{~h}$. The extraction process was repeated three times. The results show a slight improvement of arsenic extraction efficiency from 15 to 30 min of magnetic stirring. However, the use of longer extraction times did not lead to better extraction efficiencies. in the range studied. For that

Table 2

Total arsenic concentrations $\left(\mu \mathrm{g} \mathrm{g}^{-1}\right)$ found in alga samples after microwave digestion and determination by ICP-AES $(n=5)$

\begin{tabular}{lc}
\hline Alga & Total As $\left(\mu \mathrm{gg}^{-1}\right)$ \\
\hline NIES no. 9 (Sargasso) $\left(115 \pm 9 \mu \mathrm{gg}^{-1}\right)$ & $106 \pm 6$ \\
Hizikia & $88 \pm 6$ \\
Laminaria & $41 \pm 4$ \\
Chlorella & $39 \pm 3$ \\
\hline
\end{tabular}


Table 3

Total arsenic extracted, expressed as percentage \pm standard deviation $(n=3)$ found in CRM NIES no. 9 (Sargasso) dependiog on extractant nature and concentration $(5 \mathrm{~mL})$ and applying magnetic stirring for $30 \mathrm{~min}$ (three consecutive extractions)

\begin{tabular}{lll}
\hline Extractant & Concentration $\left(\mathrm{mol} \mathrm{L}^{-1}\right)$ & Total As extracted (\%) \\
\hline Water & & $64 \pm 3$ \\
Phosphoric acid & 0.1 & $63 \pm 3$ \\
& 0.3 & $59 \pm 2$ \\
& 1.5 & $64 \pm 3$ \\
Tris & 0.1 & $58 \pm 3$ \\
& 0.3 & $49 \pm 3$ \\
Methanol & & $34 \pm 2$ \\
Water/methanol (1:1 viv) & & $63 \pm 3$ \\
Water/methanol (1:9viv) & $36 \pm 2$ \\
\hline
\end{tabular}

reason, an extraction time of $30 \mathrm{~min}$ was selected as optimum when magnetic stirring was used for arsenic extraction.

In order to choose the best extractant solution for arsenic species, different solvents were tested: deionised water, phosphoric acid $\left(0.1,0.3\right.$ and $\left.1.5 \mathrm{~mol} \mathrm{~L}^{-1}\right)$, tris(hydroxymethyl)aminomethane (Tris) at $\mathrm{pH} 7.0\left(0.1\right.$ and $\left.0.3 \mathrm{~mol} \mathrm{~L}^{-1}\right)$, methanol and water/methanol mixtures $(1: 1$ and $1: 9 \mathrm{v} / \mathrm{v})$. The results (Table 3 ) show the absence of significant improvements for arsenic extraction in Sargasso material for all concentration levels tested when using phosphoric acid or Tris solutions. as well as for water/methanol mixture $(1: I \mathrm{v} / \mathrm{v})$. Nevertheless. the extraction efficiency was about $50 \%$ lower when using methanol or water/methanol mixture $(1: 9 \mathrm{v} / \mathrm{v})$. Therefore, it was concluded that Sargasso material analysed contains basically water-soluble arsenic compounds (about $65 \%$ of total arsenic present), which are extracted in water or water/methanol mixture $(1: 1 \mathrm{v} / \mathrm{v})$. In this material, methanol does not seem to improve the extraction of arsenic compounds.

The increase in the extractant volume from 5 to $10 \mathrm{~mL}$ (for water and water/methanol mixture $(1: 1 \mathrm{v} / \mathrm{v}))$ did not improve the extraction efficiencies for Sargasso material. Therefore. a volume of $5 \mathrm{~mL}$ was selected for further experiments.

The effect of ultrasonic liquid extraction (USLE) was evaluated by using an ultrasonic bath and an ultrasonic focussed probe. The experiments were carried out on Sargasso material and three consecutive extractions with $5 \mathrm{~mL}$ of water were performed. The results (Table 4) show the absence of significant differences between arsenic extraction efficiency (about $65 \%$ of the total arsenic content) for 30 min by magnetic stirring and $30 \mathrm{~s}$ by focussed probe sonication. However, slightly lower results were obtained by conventional sonication for $30 \mathrm{~min}$.

Table 4

Total arsenic extracted, expressed as percentage \pm standard deviation $(n=3)$. found in CRM NIES no. 9 (Sargasso) depending on the extraction method used (three consecutive extractions with $5 \mathrm{~mL}$ of water)

\begin{tabular}{lcl}
\hline Extraction method & Extraction time (s) & Total As extracted (\%) \\
\hline Magnetic stirring & 1800 & $64 \pm 3$ \\
Ultrasonic bath & 1800 & $60 \pm 2$ \\
Ultrasonic focussed probe & 30 & $65 \pm 3$ \\
\hline
\end{tabular}

Table 5

Total arsenic extracted expressed as percentage \pm standard deviation $(n=3)$. found in the different kinds of algae studied

\begin{tabular}{lll}
\hline Alga & \multicolumn{2}{l}{ Total As extracted (\%) } \\
\cline { 2 - 3 } & Magnetic stirring & Ultrasonic focussed probe \\
\hline NIES no. 9 (Sargasso) $^{a}$ & $64 \pm 3$ & $65 \pm 3$ \\
Hizikia & $62 \pm 3$ & $69 \pm 4$ \\
Laminaria $^{b}$ & $61 \pm 3$ & $67 \pm 4$ \\
Chiorella $^{b}$ & $59 \pm 3$ & $64 \pm 3$ \\
\hline
\end{tabular}

The extraction was carried out with $5 \mathrm{~mL}$ of deionised water and magnetic stirring for 30 min or ultrasonic focussed probe for $30 \mathrm{~s}$ (three or two consecutive extractions).

"Certified value: $115 \pm 9 \mu \mathrm{gg} \mathrm{g}^{-1}$.

b Two consecutives extractions

From results. several parameters were evaluated in order to optimise the extraction method by ultrasonic focussed probe. The effect of focussed sonication time was evaluated in the range from 30 to $300 \mathrm{~s}$. The influence of the extractant volume $(5,8$ and $10 \mathrm{~mL})$ was studied by using deionised water and water/methanol mixture $(1: 1 \mathrm{v} / \mathrm{v})$. The above mentioned studies were carried out on Sargasso material.

Neither medium composition nor longer sonication times led to better extraction efficiencies. No effect of extractant volume was observed for three consecutive extractions.

In order to evaluate the influence of alga nature. we proceeded to apply the extraction method by ultrasonic focussed probe developed to the other above mentioned algae. Table 5 shows the extraction efficiencies achieved for the four kinds of algae studied by using $5 \mathrm{~mL}$ of water and $30 \mathrm{~s}$ of focussed sonication (three consecutive extractions). The results also include those obtained by 30 min of magnetic stirring, in order to compare both extraction methods for all kinds of algae studied

Arsenic concentrations found for the third extraction step in Chlorella and Laminaria algae were lower than the detection limit. Therefore. further extraction experiments were carried out by two consecutive extraction steps for these algae, which also present a lower total arsenic content.

All types of algae analysed present a similar behaviour than Sargasso material, with about $65 \%$ of total arsenic extracted. In all cases, the rest of arsenic content was found in the solid fraction.

The same results were obtained when water/methanol mixture $(1: 1 \mathrm{v} / \mathrm{v})$ was used as extractant medium. According to the results obtained. the extraction method by ultrasonic focussed probe developed was considered more adequate for arsenic extraction in the different kinds of algae under research because of the considerable reduction in the extraction time. even though samples had to be processed one by one

\subsubsection{Clean-up of extracts from alga samples}

The final extracts obtained were processed through two cleanup methods for further HPLC analysis: filtration with $0.20 \mu \mathrm{m}$ Millex syringe filters and ultrafiltration through $10 \mathrm{kDa}$ cut-off filters. Preliminary studies with standard solutions of arsenic species studied show the absence of arsenic losses forboth meth- 


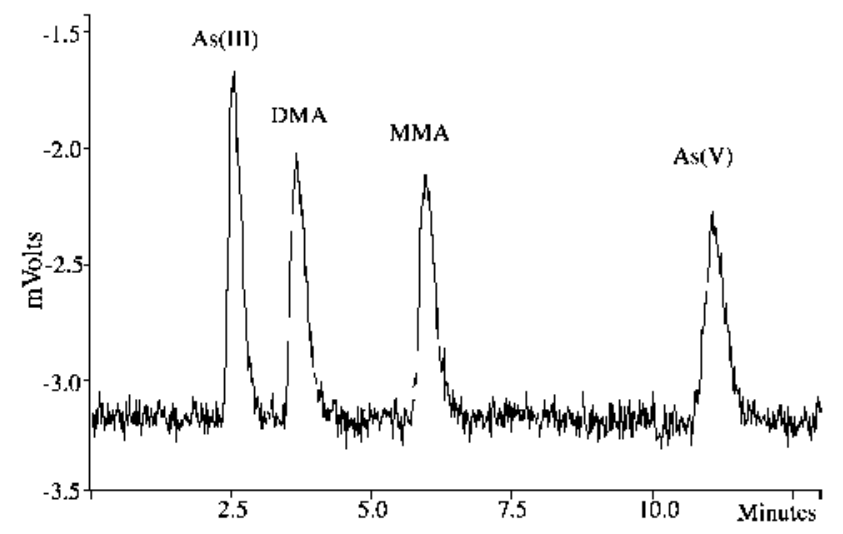

Fig. 1. [IPLC-ICP-AES chromatogram obtained for a standard solution containing $1.0 \mathrm{mg} \mathrm{l}^{-1}$ of arsenic per species.

ods. In order to process the samples, the syringe filters were inadequate because the filtration of $1 \mathrm{~mL}$ of a sample extract blocked the filters. The ultrafiltration process produced clean extracts and also allowed us to know the fraction of extracted arsenic compounds with a molecular weight lower than $10 \mathrm{kDa}$. The fraction passed through the cut-off filters was analysed by ICP-AES for determination of total arsenic content. The results show that about $100 \%$ of extracted arsenic compounds for all algae studied had a molecular weight lower than $10 \mathrm{kDa}$. Therefore, ultrafiltration process only was used as clean-up method for further experiments.
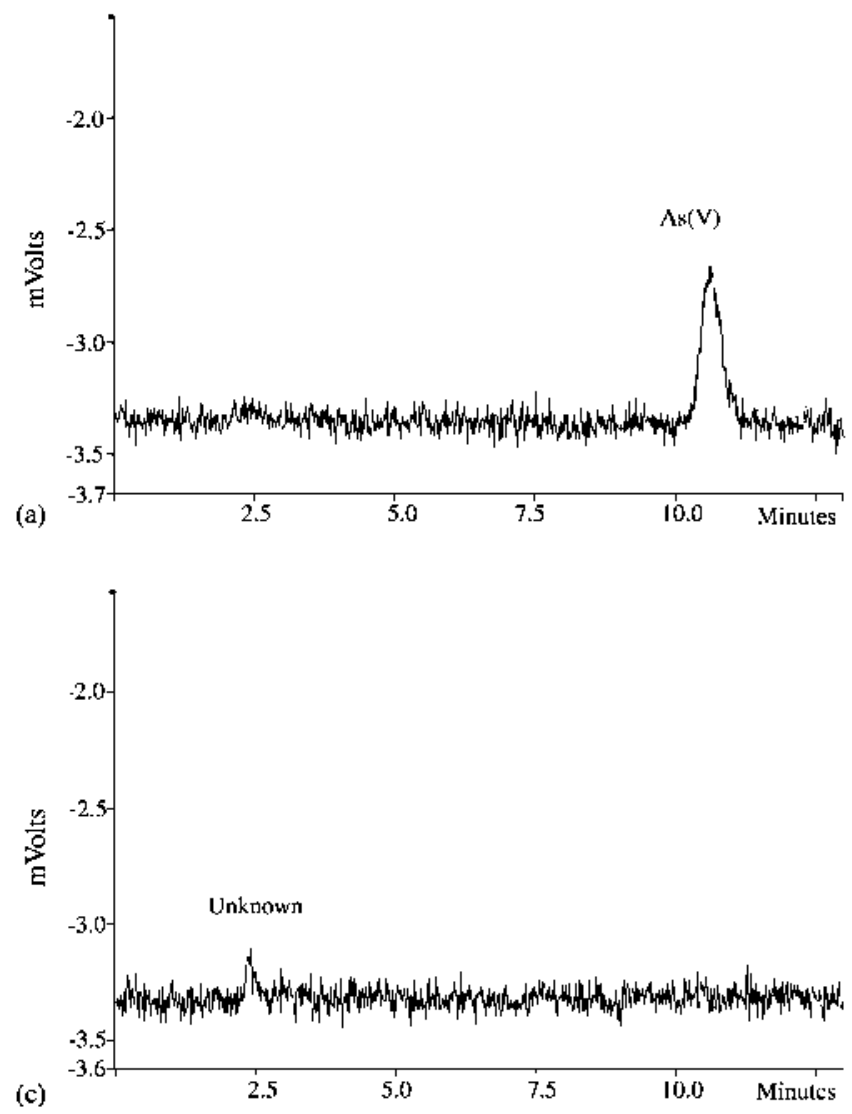

\subsubsection{Chromatographic separation}

Fig. 1 shows a HPLC-ICP-AES chromatogram obtained for a standard solution containing $1.0 \mathrm{mg} \mathrm{L}^{-1}$ of arsenic per species (As(III), DMA, MMA and As(V)). Separation of arsenic species is resolved to baseline in less than $13 \mathrm{~min}$.

Analytical characteristics were evaluated for the four arsenic compounds. The precision of the method was tested using a standard solution containing $0.50 \mathrm{mg} \mathrm{L}^{-1}$ of arsenic per species. The respective relative standard deviation was calculated from five replicate measurements under the conditions listed in Table 1. They were better than $5 \%$ in all cases.

The detection limit is defined as three times the standard deviation obtained from 10 replicate blank determinations. In this method, the signal from the blank was negligible. Therefore, detection limits were calculated using a $0.25 \mathrm{mg} \mathrm{L}^{-1}$ arsenic standard solution. Detection limits, using a $100 \mu \mathrm{L}$ sample injection volume, were $22 \mathrm{ng}$ of arsenic for As(III) and MMA and $16 \mathrm{ng}$ for $\mathrm{As}(\mathrm{V})$ and DMA.

The chromatographic method was applied to the algae studied. The chromatograms obtained for Sargassum, Hizikia, Laminaria and Chlorella algae are shown in Fig. 2. Two peaks can be distinguished in Chlorella sample (Fig. 2(d)) and one peak in the rest of algae analysed. The arsenic species were identified because of the increase in their area when arsenic species standard solutions were added. The species As(V) was identified in Sargassum, Hizikia and Chlorella samples (Fig. 2(a), (b) and (d)), with a retention time of $10.9 \pm 0.1 \mathrm{~min}$. The species DMA
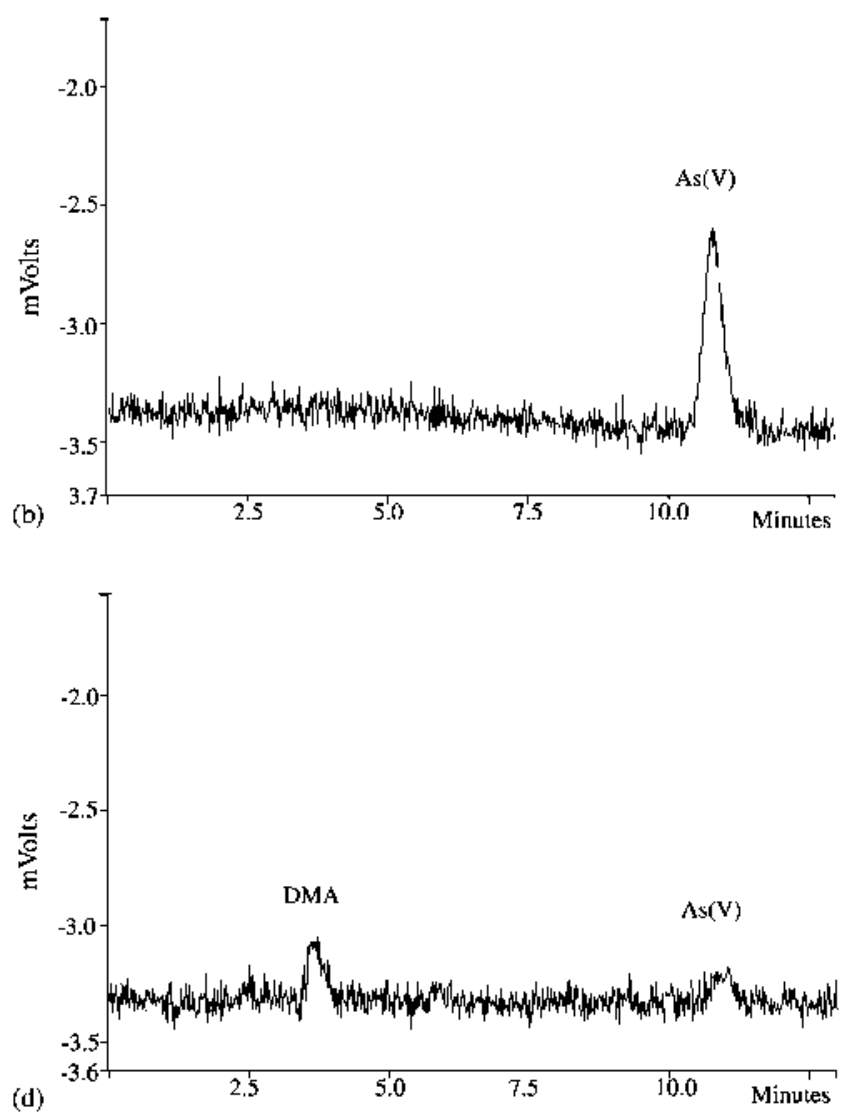

Fig. 2. HPLC-ICP-ALS chromatograms obtained for the water extract of Sargassum (a), Hizikia (b), Laminaria (c) and Chlorella (d) algae. 
Table 6

Quantitative results for arsenic species found in alga samples, expressed as $\mu \mathrm{g}^{-1}$ of arsenic (neau \pm standard deviation, $n=3$ )

\begin{tabular}{lrlll}
\hline Sample & As(V) & DMA & Total As extracted & $R^{\mathrm{a}}(\%)$ \\
\hline NIES no. 9 (Sargasso) & $38 \pm 2$ & $75 \pm 3$ & $51 \pm 3$ \\
Hizikia & $46 \pm 2$ & & $61 \pm 3$ & $75 \pm 3$ \\
Chlorella & $9 \pm 1$ & $13 \pm 1$ & $25 \pm 1$ & $88 \pm 6$ \\
\hline
\end{tabular}

a Calculated by the comparison between the sum of arsenic species concentrations and total arsenic extracted.

b Total arsenic certified material.

was also found in Chlorella alga ( $3.6 \pm 0.1 \mathrm{~min})$. However. no presence of the arsenic species studied was detected in Laminaria alga. The chromatogram (Fig. 2(c)) shows the presence of an unknown arsenic species, which eluted in the dead volume. We did not find any presence of As(III) and MMA species in the algae analysed. Therefore, if these arsenic species are present, they cannot be detected with the method used

Species quantification was carried out by HPLC standard addition method and the results are shown in Table 6 . Recoveries were calculated by the comparison between the sum of arsenic species concentrations and total arsenic extracted. The arsenic recovery for Sargasso material was lower than those found for Hizikia and Chlorella algae. Therefore, sample matrix seems to be an important point to consider, because it may cause the retention of arsenic extracted on the HPLC column [26]. Another explanation for this might be that arsenic species are present at concentration levels lower than detection limits of the method.

\section{Conclusions}

In this paper a versatile method for arsenic extraction assisted by ultrasonic focussed probe applied to speciation analysis is presented. The extraction efficiencies obtained with $30 \mathrm{~s}$ were comparable to those obtained for $30 \mathrm{~min}$ of magnetic stirring.

The algae analysed shows the presence of water-soluble arsenic compounds (about $65 \%$ of total arsenic present). Methanol or water/methanol mixture $(1: 9 \mathrm{v} / \mathrm{v})$ provided lower extraction efficiencies than water.

The use of cut-off filters is an adequate clean-up method for algae extracts, which provides more information on the arsenic compounds present in the samples. The fraction of arsenic compounds extracted with a molecular weight lower than $10 \mathrm{kDa}$ was about $100 \%$ for all samples studied.

The species As(V) was identified in Hizikia $\left(46 \pm 2 \mu \mathrm{gg}^{-1}\right)$. Sargassum $\left(38 \pm 2 \mu \mathrm{gg}^{-1}\right)$ and Chlorella $\left(9 \pm 1 \mu \mathrm{gg}^{-1}\right)$ algae. The species DMA was also detected in Chlorella alga $\left(13 \pm 1 \mu \mathrm{gg}^{-1}\right)$. However, for Laminaria alga only an unknown arsenic species was detected, which eluted in the dead volume.

From these results, it can be concluded that the use of HPLC coupled to ICP-AES is adequate for arsenic speciation in algae containing relative high arsenic levels. However, future research will focus on the coupling of hydride generation in order to enhance the sensitivity.

\section{Acknowledgements}

The authors would like to thank the "Secretaria de Estado de Política Científica y Tecnológica-Ministerio de Ciencia y Tecnología" for financial support (project FEDER UNPM0033015). Thanks to Varian Spain for providing the argon used in this research and to Ph.D. Christian Dietz for revising the manuscript.

\section{References}

[1] D.J.H. Phillips, Aquat. Toxicol. 16 (1990) 151.

[2] P. Fodor, in: L. Ebdon, L. Pitts, R. Cornelis, H. Crews, O.F.X. Donard. Ph. Quevauviller (Eds). Trace Element Speciation for Environment. Food and Health, The Royal Society of Chemistry, Cambridge, UK, 2001 (Chapter 11).

[3] Z. Gong. X. Lu, M. Ma, C. Watt. X.C. Le, Talanta 58 (2002) 77.

[4] R. Eisler, Handbook of Chenical Risk Assessment Health Hazards to Humans, Plants and Animals, Metalloids, Radiation. Cumulative Index to Chemicals and Species, vol. 3, CRC Press, Boca Raton, FL, 2000 (Chapter 28).

[5] V.M. Dembitsky, T. Rezanka, Plant Sci. 165 (2003) 1177.

[6] E. Schmeisser, W. Goessler, N. Kienzl, A. Francesconi, Anal. Chem. 76 (2004) 418 .

[7] G. Raber. K.A. Francesconi, K.J. Irgolic. W. Goessler, Fresen. J. Anal. Chem. 367 (2000) 181.

[8] K.A. Francesconi, J.S. Edmonds, in: J.O. Nriagu (Ed.), Arsenic in the environment. Part l, Cycling and Characterization, John Wiley \& Sons, New York. 1994, pp. 221-263.

[9] K.A. Francesconi. D.A. Hunter, B. Bachmanu, G. Raber, W. Goessler. Appl. Organomet. Chem. 13 (1999) 669.

[10] J.S. Edmonds, Bioinorg. Med. Chem. Lett. 10 (2000) 1105.

[11] C. Wei. W. Li, C. Zhang, M. Van Hulle, R. Cornelis, X. Zhang, J. Agric. Food Chem. 51 (2003) 5176

[12] S. McSheehy, J. Szpunar, R. Morabito, P. Quevauviller, Trends Anal. Chem. 22 (2003) 191.

[13] J. Szpunar, Analyst 125 (2000) 963.

[14] S. Mesheehy, P. Pohl, D. Vélez. J. Szpunar, Anal. Bioanal. Chen. 372 (2002) 457 .

[15] K.A. Francesconi, Appl. Organomet. Chem. 16 (2002) 437.

[16] S. Karthikeyan. S. Hirata, Appl. Organomet. Chem. 18 (2004) 323.

[17] R. Tukai, W.A. Maher, I.J. MeNaught. M.J. Ellwood. Anal. Chin. Acta 457 (2002) 173

[18] D. Kuelunelt, K.J. Irgolic, W. Goessler, Appl. Organomet. Chem. 15 (2001) 445

[19] V.W.M. Lai, W.R. Cullen, C.F. Harrington, K.J. Reimer, App]. Organomet. Chem. 11 (1997) 797.

[20] C.F. Harrington, A.A. Ojo, V.W.M. Lai, K.J. Reimer, W.R. Cullen, Appl. Organomet. Chen. 11 (1997) 931.

[21] V.W.M. Lai, W.R. Cullen, C.F. Harrington, K.J. Reimer. Appl. Organonet. Chem. 12 (1998) 243.

[22] S. McSheehy, P. Pohl, R. Lobinski, J. Szpunar, Anal. Chin. Acta 440 (2001) 3 .

[23] S. MeSheehy, M. Marcinek, H. Chassaigne, J. Szpunar, Anal. Chin. Acta $410(2000) 71$.

[24] T. Dagnac, A. Padró, R. Rubio, G. Rauret, Anal. Chim. Acta 364 (1998) 19.

[25] T.J. Mason, in: R.G. Compton, S.G. Davies, J. Evans, L.F. Gladden (Eds.). Sonochemistry, Oxford University Press, Oxford, 1999 (Chapter 3).

[26] R. Wahlen, S. McSheelyy, C. Scriver, Z. Mester, J. Anal. Atom. Spectron. 19 (2004) 876 . 